\title{
The association between housing and food insecurity among medically underserved cancer patients
}

\author{
Francesca Gany ${ }^{1,2}$ (1) - Irina Melnic ${ }^{1}$. Julia Ramirez ${ }^{1} \cdot$ Minlun $\mathrm{Wu}^{1} \cdot$ Yuelin $\mathrm{Li}^{1} \cdot$ Luke Paolantonio $^{1}$. \\ Nicole Roberts-Eversley ${ }^{1}$. Victoria Blinder ${ }^{1,2}$. Jennifer Leng ${ }^{1,2}$
}

Received: 5 January 2021 / Accepted: 26 April 2021 / Published online: 24 June 2021

(c) The Author(s), under exclusive licence to Springer-Verlag GmbH Germany, part of Springer Nature 2021

\begin{abstract}
Purpose To assess the prevalence of socioeconomic needs and associations between housing characteristics and food insecurity among low-income cancer patients, among whom housing and food insecurity are particularly prevalent.

Methods Low-income cancer patients in active treatment $(N=1618)$ were enrolled in a comprehensive patient navigation program. Food insecurity was assessed using the 18-item US Department of Agriculture US Household Food Security Survey Module. Participants self-reported their need for assistance with housing issues/type of assistance needed, perception of overcrowding, satisfaction with living situation, and household density via a cross-sectional survey. Descriptive analyses, cross-tabulations and tests of proportions, and binary logistic regression were used in data analyses.

Results Seventy percent of patients were food insecure. Housing characteristics associated with food insecurity were homelessness or living in sheltered/supportive housing (83.3\% food insecure), renting (71.9\%), and homeownership (58.1\%; $p<.001$ ); living situation satisfaction (not satisfied, $79.4 \%$; somewhat satisfied, $25.6 \%$; very satisfied, $66 \%$; $p<.001$ ); need of housing assistance $(79.2 \% ; p<.001)$, and feeling crowded in their living unit $(77.6 \% ; p<.05)$. Associations of living unit type with food insecurity were significant in the binary logistic regression model (renters $1.68 \mathrm{OR}$, homeless/sheltered housing 2.80 OR vs homeowners).

Conclusion The vulnerability to food insecurity of patients in this low-income sample was underlined by the high rates found, and clear associations with housing characteristics of homelessness, housing assistance needs, and feeling overcrowded were identified. These results could help shape priorities around screening patients for nutrition and housing needs and developing interventions to address them.
\end{abstract}

Keywords Food insecurity $\cdot$ Housing $\cdot$ Household density $\cdot$ Overcrowding $\cdot$ Cancer $\cdot$ Social determinants of health

\section{Background}

Low-income, immigrant, and minority cancer patients, for whom a cancer diagnosis can be an extreme financial burden added to an already financially precarious situation [1], can be particularly affected by poor housing conditions and food insecurity [2]. Adequate housing and food are two

Francesca Gany

ganyf@mskcc.org

1 Department of Psychiatry and Behavioral Sciences, Immigrant Health and Cancer Disparities Service, Memorial Sloan Kettering Cancer Center, 485 Lexington Avenue, 2nd Floor, New York, NY 10017, USA

2 Department of Medicine, Department of Public Health, Weill Cornell Medical College, New York, NY, USA fundamental human rights and are essential contributors to health [3-6]. Housing insecurity has no standard definition but can include affordability, safety, quality, and overcrowding issues, staying with relatives, and housing loss [7]. Food insecurity arises with inadequate and inconsistent access to enough food for an active healthy life [8]. Underserved New York City (NYC) cancer patients have a high number of characteristics associated with housing-related issues and food insecurity, including race/ethnicity, immigrant background, education level, and low income [9, 10].

Poor housing indicators are associated with negative physical and mental health outcomes and increased morbidity from infectious diseases, chronic illnesses, and injuries [3-6]. Overcrowding is negatively associated with mental health, coping with stress, social relationships, sleep, and psychological distress [11-13]. Housing insecurity is also a 
barrier to having a usual source of health care and is associated with postponing medical care, missing appointments, and higher hospitalization rates among low-income adults [14]. A qualitative study among NYC cancer patients/survivors identified housing needs as housing expenses (e.g., rent, mortgage, and utilities), housing loss, crowded/unstable housing, and housing conditions, accessibility, and safety [2].

Cancer patients who are food insecure are more likely to have poorer functional, social, and emotional well-being [14-17], are at higher risk for depression [18], and are more likely to have missed appointments and treatment delays and interruptions [18]. Food insecurity is associated with increased rates of diabetes, hypertension, hyperlipidemia, anemia, depression, stress, and anxiety [19-21]. Food insecure individuals are less likely to seek needed medical care and more likely to postpone medications and miss treatment appointments than food secure patients [18, 22].

Social determinants of health, the non-medical determinants of health outcomes that can include housing and food needs, are often interrelated [23]. In the biobehavioral theory of health, housing insecurity is an environmental and emotional contributor to food insecurity [24]. However, housing and food insecurity are rarely assessed in the cancer clinical encounter, and there is no literature on the association between housing characteristics and food insecurity among cancer patients. This study assessed the prevalence of socioeconomic needs and associations between housing characteristics and food insecurity among predominantly low-income, immigrant, and minority cancer patients enrolled in a comprehensive patient navigation program in NYC. The results could help shape priorities around screening patients for, and implementing interventions to address, cancer patients' social determinants of health-related outcomes.

\section{Methods}

\section{Design and participants}

This study focused on a nested cohort of cancer patients enrolled in the Integrated Cancer Care Access Network (ICCAN) [25] from 2012 through 2017, available to patients at eleven NYC cancer clinics located in safety net hospitals and academic medical centers. The primary aim of the ICCAN program is to address cancer disparities among NYC's low-income immigrant and minority communities by working to increase their access to care and essential needs. Patients were enrolled in the program at the beginning of or at another point during their cancer treatment and remained enrolled for the duration of their treatment and for up to a year afterwards. Patients were screened for housing issues and food insecurity at intake.
Cancer patients in active treatment were approached by bilingual access facilitators who administered an intake survey in English, Spanish, or Mandarin, according to patient preference. Access facilitators were trained in administering the intake questionnaire during a face-to-face interview and addressed any questions during the survey administration. A detailed description of the study methodology and intake survey has been previously published [25]. This study was approved by the Institutional Review Board of Memorial Sloan Kettering Cancer Center.

\section{Measures}

The routine ICCAN needs assessment questionnaire was administered to all participants at intake, collecting information on sociodemographic characteristics, medical history, cancer treatment history, and financial, housing, food, transportation, and other non-medical needs.

Participants self-reported their need for assistance with housing issues. Patients were asked "Do you feel that you need assistance with housing issues?" with a yes/no response format and an option to specify type of housing assistance needed. In addition, patients were asked "Do you have any of the following problems with your living unit?" and provided with a multiple-choice list, including no stove/oven, heat, water, hot water, electricity, or windows; flooding; and an "other" option.

To assess perception of overcrowding and satisfaction with one's living situation, participants were asked, "Do you feel that your living unit is too crowded?" with a yes/no response format and "Overall, how satisfied are you with your living situation?" with answer choices of not satisfied, somewhat satisfied, or very satisfied.

Household density was determined according to the US Department of Housing and Urban Development standard, which is based on the number of people per bedroom. Households with $>2$ people per bedroom were categorized as high density and households with $\leq 2$ people per bedroom were categorized as low density [26].

Food insecurity was assessed using the US Department of Agriculture (USDA) US Household Food Security Survey Module [27]. This survey includes 18 items that assess household food security over the preceding 12 months [27]. Survey items address, for example, whether individuals ran out of food before being able to buy more, cut the size of or skipped meals, were hungry, did not eat for a whole day, and/or lost weight due to not having enough money for food.

\section{Statistical analyses}

Descriptive analyses were performed to examine sociodemographic and housing characteristics: means and standard deviations for continuous variables and percentages for 
categorical variables. Food security categories were calculated based on the Food Security Survey Module (USDA) guidelines: raw score $0-2=$ food secure, raw score $>2=$ food insecure [26, 27].

Cross-tabulations and tests of proportions were used to investigate the differences in housing characteristics between food secure households and food insecure households. Significance $(p)$ values were obtained using Pearson chi-squares for most variables, and the Fisher's exact test was used for small groups $(n<5)$. All tests were two sided and a $p$ value of $<.05$ was considered statistically significant.

Covariates with a statistically reliable univariate association were entered into a binary logistic regression to examine to what extent food insecurity was associated with housing variables. The 10-event-per-covariate rule was considered to minimize model overfit [28]. We did not conduct any falsediscovery-rate adjustments for multiple statistical comparisons [29]. The logistic regression examined the housing predictors of food insecurity. All missing values were excluded from analyses and all statistical analyses were conducted using SPSS version 24 [30].

\section{Results}

Participant characteristics $(N=1618)$ are shown in Table 1. Most were female (71.6\%) and/or born outside the USA $(78.0 \%)$ with a mean age of 57 (13 SDs). Almost half (47.6\%) were non-Hispanic Black, and just over one-fifth $(22.7 \%)$ were Hispanic. Two-thirds $(66.3 \%)$ were single (separated, divorced, widowed, never married). Most (75.7\%) were unemployed. The most frequent cancer diagnoses were breast cancer (43.6\%), followed by prostate $(9.2 \%)$ and lung (6.9\%). Many (43.8\%) had completed less than a high school education ( $<12$ th grade), including $12.1 \%$ with up to a 5 th grade education. Many (41.8\%) participants reported speaking English less than "very well." A high proportion of participants (91.7\%) had health care coverage, most of which was public: $32.6 \%$ had Medicaid for the treatment of an emergency medical condition, $46.3 \%$ Medicaid, 6.2\% Medicare, 9.1\% both Medicaid and Medicare, and $5.7 \%$ private insurance. Almost one-fourth (23.5\%) had no household income, and $68.8 \%$ were food insecure.

Table 2 shows participants' housing characteristics and their self-reported assessments of their living conditions. Most (77.4\%) participants lived in rental units, including $19.0 \%$ of the study population in public housing, and almost one-fifth were homeowners (18.7\%). A few were in supportive housing $(1.3 \%)$ or a shelter/homeless $(0.3 \%)$. Over one-fifth $(22.0 \%)$ lived in high-density households ( $>2$ individuals per bedroom), and $16.3 \%$ felt that their living unit was overcrowded. One hundred eight (7.1\%) participants reported problems with their living unit, including having no heat $(13.0 \%)$, hot water $(13.0 \%)$, stove $(12.0 \%)$, windows (5.6\%), and/or electricity (4.6\%), and some (5.6\%) had experienced home flooding. Most participants were very $(59.1 \%)$ or somewhat (30.6\%) satisfied with their living situation, and $10.3 \%$ were not satisfied. Assistance was needed with housing (16.4\%), transportation (59.1\%), and acquiring nutrition information (90.0\%).

Table 3 summarizes the relationships between housing and characteristics and satisfaction and food security status. Patients who were homeless or lived in a shelter/supportive housing were most likely to be food insecure (83.3\%), followed by those who lived in a rental unit $(71.9 \%)$, and those who lived in a private unit that they owned $(58.1 \%$; $p<.005)$. Patients who were not satisfied with their living situation were more likely to be food insecure $(79.4 \%)$ than those who were very satisfied $(63.0 \% ; p<.000)$. Patients who needed housing assistance were more likely to be food insecure (79.2\%) than those who did not need assistance $(66.0 \% ; p<.001)$, and those who felt crowded in their living unit were more likely to be food insecure (77.6\%) than those who did not feel crowded $(66.9 \% ; p<.011)$. Patients who needed nutritional information were more likely to be food insecure $(71.4 \%)$ than food secure $(22.4 \% ; p=.000)$. There was no significant association of race/ethnicity with food security status $(p=.098)$.

Housing factors that were significant in predicting food insecurity in the univariate analyses (living unit type, living situation satisfaction, need for assistance with housing, and feeling overcrowded) were further analyzed in a binary logistic regression to examine their relative influence on food insecurity (Table 4). Living unit type was significantly associated with food insecurity: patients who lived in a shelter/ supportive housing or who were homeless were more likely to be food insecure (OR, 2.803; 95\% CI, 0.584-13.445) than patients who owned their housing unit. Patients who lived in a rental unit were also more likely to be food insecure (OR, 1.680; 95\% CI, 1.116-2.420) than patients who owned their housing unit.

\section{Discussion}

We found that low-income, immigrant, and minority cancer patients who were homeless or lived in sheltered/supportive housing, lived in a rental unit, were not satisfied with their living situation, reported a need for housing assistance, and/or reported feeling too crowded were more likely to be food insecure than others. Housing and food insecurity are particularly prevalent among low-income minority patients, putting them at greater risk of associated negative outcomes. However, this is the first study to examine associations between housing and food insecurity among cancer patients. 
Table 1 Frequencies $\left(N=1618^{\mathrm{a}}\right)$

\begin{tabular}{|c|c|c|}
\hline Characteristics & Categories & Total sample, no. (\%) \\
\hline \multirow[t]{2}{*}{ Gender $(n=1618)$} & Female & $1158(71.6)$ \\
\hline & Male & $460(28.4)$ \\
\hline Age $(n=1618)$, mean $(\mathrm{SD})$ & & $57(13)$ \\
\hline \multirow[t]{4}{*}{ Race $(n=1553)$} & Non-Hispanic Black & $727(46.7)$ \\
\hline & Hispanic/Latino & $353(22.7)$ \\
\hline & Non-Hispanic White & $119(7.4)$ \\
\hline & Some other race & $354(23.2)$ \\
\hline \multirow[t]{9}{*}{ Education level $(n=1587)$} & None & $33(2.1)$ \\
\hline & Kindergarten-2nd grade & $26(1.6)$ \\
\hline & 3 rd -5 th grade & $133(8.4)$ \\
\hline & 6th-8th grade & $252(15.9)$ \\
\hline & 9th-11th grade & $251(15.8)$ \\
\hline & 12th grade/HS graduate & $524(33.0)$ \\
\hline & Some college & $161(10.1)$ \\
\hline & College graduate & $170(10.7)$ \\
\hline & Post college/graduate school & $37(2.3)$ \\
\hline \multirow[t]{6}{*}{ Marital status $(n=1608)$} & Married & $542(33.7)$ \\
\hline & Partnered & $38(2.4)$ \\
\hline & Divorced & $136(8.5)$ \\
\hline & Separated & $132(8.2)$ \\
\hline & Widowed & $155(9.6)$ \\
\hline & Single & $605(37.6)$ \\
\hline \multirow[t]{5}{*}{ Employment status $(n=1565)$} & Employed (full time) & $31(2.0)$ \\
\hline & Employed (part time) & $89(5.7)$ \\
\hline & Unemployed & $1185(75.7)$ \\
\hline & Retired & $256(16.4)$ \\
\hline & Student & $4(0.3)$ \\
\hline \multirow[t]{6}{*}{ Cancer diagnosis $(n=1485)$} & Breast & $648(43.6)$ \\
\hline & Prostate & $137(9.2)$ \\
\hline & Lung & $103(6.9)$ \\
\hline & Colon & $103(6.9)$ \\
\hline & Lymphoma & $57(3.8)$ \\
\hline & Other cancer & 437 (29.6) \\
\hline \multirow[t]{4}{*}{ Monthly household income $(n=929)$} & No income & $218(23.5)$ \\
\hline & Low income (\$1-\$999) & $294(31.6)$ \\
\hline & Middle income $(\$ 1000-\$ 2300)$ & $351(37.8)$ \\
\hline & High income (> \$2300) & $66(7.1)$ \\
\hline \multirow[t]{4}{*}{ English proficiency $(n=1610)$} & Very well & $938(58.3)$ \\
\hline & Well & $191(11.9)$ \\
\hline & Not well & $275(17.1)$ \\
\hline & Not at all & $206(12.8)$ \\
\hline \multirow[t]{3}{*}{ Language $(n=1529)$} & English & $1012(66.2)$ \\
\hline & Spanish & $429(28.1)$ \\
\hline & Other & $88(5.8)$ \\
\hline \multirow[t]{2}{*}{ Born in USA $(n=1390)$} & Yes & $306(22.0)$ \\
\hline & No & $1084(78.0)$ \\
\hline \multirow[t]{2}{*}{ Health insurance status $(n=1494)$} & Uninsured & $124(8.3)$ \\
\hline & Insured & $1370(91.7)$ \\
\hline
\end{tabular}


Table 1 (continued)

\begin{tabular}{lll}
\hline Characteristics & Categories & Total sample, no. (\%) \\
\hline Health insurance type $(n=1301)$ & Emergency Medicaid & $424(32.6)$ \\
& Medicaid & $602(46.3)$ \\
& Medicare & $81(6.2)$ \\
Food security $(n=792)$ & Medicaid \& Medicare & $119(9.1)$ \\
& Private & $75(5.7)$ \\
& Food secure & $247(31.2)$ \\
& Food insecure & $545(68.8)$ \\
\hline
\end{tabular}

${ }^{a}$ Missing data excluded

Table 2 Housing quality and other needs $(N=1618)$

\begin{tabular}{lll}
\hline Housing characteristics & Categories & Total sample, no. (\%) \\
\hline Living unit type $(n=1614)$ & Rental & $1250(77.4)$ \\
& Private & $317(18.7)$ \\
& Supportive housing & $21(1.3)$ \\
& Shelter/homeless & $5(0.3)$ \\
Housing density $(n=1360)$ & Other & $21(1.3)$ \\
& Overcrowded $(>2$ PPB) & $299(22.0)$ \\
Public housing $(n=1541)$ & Not overcrowded & $1061(78.0)$ \\
Problems with living situation $(n=1541)$ & Yes & $293(19.0)$ \\
& No & $1248(81.0)$ \\
Feeling too crowded $(n=1611)$ & No & $1403(92.9)$ \\
& Yes & $108(7.1)$ \\
issues $(n=1590)$ & No stove & $13(12.0)$ \\
& No heat & $14(13.0)$ \\
Satisfaction with living situation $(n=1618)$ & No water & $14(13.0)$ \\
& Flooding & $6(5.6)$ \\
& No electricity & $5(4.6)$ \\
& No windows & $6(5.6)$ \\
& Not satisfied & $166(10.3)$ \\
& Somewhat satisfied & $495(30.6)$ \\
& Very satisfied & $957(59.1)$ \\
& Yes & $260(16.4)$ \\
& No & $1330(83.6)$ \\
& Yes & $262(16.3)$ \\
& No & $1349(83.4)$ \\
\hline
\end{tabular}

Abbreviation: $P P B$, persons per bedroom
This study recruited largely from NYC public hospitals that serve a disproportionate share of the city's lowincome and uninsured population, and $95 \%$ of the hospitals' patients are of racial/ethnic minority backgrounds [31]. These hospitals serve areas designated as medically underserved by the federal Health Resources and Services Administration and have two to three times as many uninsured patients as other NYC hospitals [31]. One study clinic was located in a Bronx community district in which the cancer mortality rate was $30 \%$ higher than for NYC overall, according to a 2018 report; $31 \%$ of residents lived in poverty, $16 \%$ were unemployed, and $60 \%$ of renters were rent burdened (vs. NYC averages of $20 \%, 9 \%$, and $51 \%$, respectively), meaning that they spent over $30 \%$ of household income on rent [32]. In the East Harlem district of another study clinic, the cancer mortality rate was $27 \%$ higher than for NYC overall; $23 \%$ of residents lived in poverty, $11 \%$ were unemployed, and $48 \%$ of renters were 
Table 3 Housing/demographic characteristics and associations with food insecurity $(n=792)$

\begin{tabular}{|c|c|c|c|c|}
\hline Housing characteristics & Categories & $\begin{array}{l}\text { Food secure } \\
(n=247), \text { no. }(\%)\end{array}$ & $\begin{array}{l}\text { Food insecure } \\
(n=545), \text { no. }(\%)\end{array}$ & $p$ value \\
\hline \multirow[t]{4}{*}{ Race $(n=763)$} & Non-Hispanic Black & $128(35.2)$ & $236(64.8)$ & .098 \\
\hline & Hispanic/Latino & $30(22.1)$ & $106(77.9)$ & \\
\hline & Non-Hispanic White & $13(22.0)$ & $46(78.0)$ & \\
\hline & Some other race & $65(33.5)$ & $139(66.5)$ & \\
\hline \multirow[t]{4}{*}{ Living unit type $\mathrm{e}^{\mathrm{a}}(n=792)$} & Rental & $169(28.1)$ & $432(71.9)$ & .005 \\
\hline & Private & $70(41.9)$ & $97(58.1)$ & \\
\hline & $\begin{array}{l}\text { Shelter/supportive housing/ } \\
\text { homeless }\end{array}$ & $2(16.7)$ & $10(83.3)$ & \\
\hline & Other & $4(44.4)$ & $5(55.6)$ & \\
\hline \multirow[t]{4}{*}{ Monthly household income $(n=450)$} & No income & $35(28.0)$ & $90(72.0)$ & .087 \\
\hline & Low income & $42(29.0)$ & $103(71.0)$ & \\
\hline & Middle income & $47(32.2)$ & $99(67.8)$ & \\
\hline & High income & $17(50.0)$ & $17(50.0)$ & \\
\hline \multirow[t]{2}{*}{ Household density $(n=673)$} & Overcrowded & $47(33.3)$ & $94(66.7)$ & .355 \\
\hline & Not overcrowded & $156(29.3)$ & $376(7.7)$ & \\
\hline \multirow[t]{2}{*}{ Public housing $(n=749)$} & Yes & $51(33.8)$ & $100(66.2)$ & .495 \\
\hline & No & $185(3.9)$ & $413(69.1)$ & \\
\hline \multirow[t]{2}{*}{ Problems with living situation $(n=743)$} & Yes & $15(23.4)$ & $49(76.6)$ & .162 \\
\hline & No & $218(32.1)$ & $461(67.9)$ & \\
\hline \multirow[t]{6}{*}{ Problems with living situation $(n=64)$} & No stove ${ }^{\mathrm{a}}$ & $2(28.6)$ & $5(71.4)$ & .641 \\
\hline & No heat & $6(2.0)$ & $24(8.0)$ & .231 \\
\hline & No water ${ }^{\mathrm{a}}$ & $3(33.3)$ & $6(66.7)$ & .507 \\
\hline & Flooding $^{\mathrm{a}}$ & $1(10.0)$ & $0(0.0)$ & .285 \\
\hline & No electricity $^{\mathrm{a}}$ & $0(0.0)$ & $2(100.0)$ & .513 \\
\hline & No windows ${ }^{\mathrm{a}}$ & $0(0.0)$ & $1(100.0)$ & .717 \\
\hline \multirow[t]{3}{*}{ Satisfaction with living situation $(n=792)$} & Not satisfied & $20(2.6)$ & $77(79.4)$ & .000 \\
\hline & Somewhat satisfied & $67(25.6)$ & $195(74.4)$ & \\
\hline & Very satisfied & $160(37.0)$ & $273(63.0)$ & \\
\hline \multirow[t]{2}{*}{ Self-reported need for housing assistance $(n=786)$} & Yes & $33(2.8)$ & $126(79.2)$ & .001 \\
\hline & No & $213(34.0)$ & $414(66.0)$ & \\
\hline \multirow[t]{2}{*}{ Feeling too crowded $(n=789)$} & Yes & $34(22.4)$ & $118(77.6)$ & .011 \\
\hline & No & $211(33.1)$ & $426(66.9)$ & \\
\hline
\end{tabular}

Table 4 Binary logistic regression on food insecurity $(n=771)$

\begin{tabular}{|c|c|c|c|c|c|}
\hline Variables & & Coefficient & Odds ratio & $95 \% \mathrm{CI}$ & $p$ value \\
\hline \multirow[t]{3}{*}{ Living unit type } & Private & ref & ref & ref & \\
\hline & Rental & .519 & 1.68 & $(1.116-2.420)$ & .005 \\
\hline & $\begin{array}{l}\text { Shelter/supportive } \\
\text { housing/homeless }\end{array}$ & 1.031 & 2.803 & $(.584-13.445)$ & .015 \\
\hline \multirow[t]{3}{*}{ Satisfaction with living situation } & Very satisfied & ref & ref & ref & \\
\hline & Somewhat satisfied & .352 & 1.422 & $(.976-2.072)$ & .067 \\
\hline & Not satisfied & .471 & 1.601 & $(.855-2.999)$ & .142 \\
\hline \multirow{2}{*}{$\begin{array}{l}\text { Self-reported need for assistance } \\
\text { with housing issues }\end{array}$} & Yes & ref & ref & ref & \\
\hline & No & -.33 & .719 & $(.446-1.158)$ & .175 \\
\hline \multirow[t]{2}{*}{ Feeling too crowded } & Yes & ref & ref & ref & \\
\hline & No & -.143 & .867 & $(.542-1.388)$ & .552 \\
\hline
\end{tabular}


rent burdened (vs. 9\%, 5\%, and 40\%, respectively, for the adjacent Upper West Side) [32]. Therefore, the characteristics of our patient population included high frequencies of characteristics associated with housing issues and food insecurity and that reflect long-standing structural inequities $[9,10]$. Indeed, the food insecurity rate was $70 \%-$ five times the NYC average of $14.4 \%$ and six times the national average of $11.8 \%$ [33]. These structural issues exist in vulnerable communities throughout the USA, as recently illustrated by the vast racial/ethnic disparities in COVID-19 health outcomes nationally [34].

Other US studies have found associations between housing and food insecurity. One study in Los Angeles found that respondents who had experienced homelessness in the past 5 years were at high risk of food insecurity (OR, 5.6) [9]. In a Chicago study of marginally housed individuals, $75 \%$ were food insecure and 53\% met severe food insecurity criteria [35]. A qualitative study among low-income Latino immigrants in rural US areas found that the families with the highest housing costs had "consistent" (long-term) food insecurity and that housing issues drained resources away from meeting food needs [36].

According to the biobehavioral theory of health, human behavior is shaped by a complex interplay of social and environmental exposures and biobehavioral responses [24]. At the environmental level, housing challenges, such as high housing costs, overcrowding, lack of kitchen access, and homelessness, create obstacles to the acquisition, storage, and preparation of healthful foods. Also, affordable healthful foods may not be readily available in low-income communities, where energy-dense nutritionally poor foods are often cheaper, heavily advertised, and more readily available than nutritious foods, and nutritional knowledge can be lacking [24]. Within this framework, income alone cannot fully address food insecurity and diet quality, and environmental factors, including housing, must also be addressed.

Living in a rental unit was associated with food insecurity and the overcrowding rate was at least 4 times the citywide average of $4.6 \%$ [37]. Racial/ethnic minorities in NYC are more likely than non-Hispanic Whites to live in rented and/or overcrowded housing and to be housing cost burdened [37]. Among low-income NYC renters, almost half (45.6\%) are severely rent burdened, spending at least $50 \%$ of household income on gross rent [37]. Furthermore, immigrants without status are not eligible for government benefits related to housing, such as subsidized housing, housing vouchers, and public housing programs, so they may find it particularly hard to find assistance with housing costs [38].

Some of our participants were homeowners, and as household income is affected by cancer-related income and/or job loss, home maintenance, taxes, and mortgage payments may become difficult for low-income cancer patients to afford. In a qualitative study of cancer patients and survivors with housing needs, the participants who had been homeowners when they commenced treatment had lost their homes to foreclosure after falling behind on mortgage payments [2]. Potentially burdensome housing costs and home loss, and the stress they entail, could be contributing factors to food insecurity among renters and homeowners.

Socioeconomic hardships, such as poor housing conditions and food insecurity, could exacerbate low-income, immigrant, and minority cancer patients' already elevated risk of poor cancer health outcomes [39]. However, there is the potential to ameliorate this. Patient navigation programs, for example, can help address these hardships. In an assessment of ICCAN patients in urgent need of financial support, $86 \%$ reported that navigation services had helped them to attend medical appointments and $72 \%$ that services had decreased their care worries [25]. When possible, cancer clinics should have designated patient navigators, nutritionists, education and outreach coordinators, and social workers for comprehensive and timely case management assistance, and ideally, they should be bilingual in languages spoken in the local community. Printed information should also be available in languages spoken in the local community. Cancer clinics should establish partnerships, such as with community-based and legal service organizations, to enable sustainable access to additional resources. Patients should be screened regularly over their treatment course to monitor for the emergence or worsening of housing and food security issues as the financial strains of cancer treatment and survivorship often increase over time [40]. Successful patient navigation requires clear guidelines, definition, and rigorous testing of outcomes and processes [41]. National initiatives, such as the National Cancer Institute Patient Navigation Research Program, have been created to design and evaluate patient navigation programs for vulnerable populations [41]. Clear metrics should be established to assess successful outcomes of patient navigation targeted to vulnerable cancer populations who are food and housing insecure. Policy advocacy can then support implementation of evidencebased successful patient navigation programs on the local, state, and national levels.

Patient navigators and social workers who work with housing insecure cancer patients can help them to identify and apply for some existing resources. For example, the specific housing problems that participants who were renters reported in our study are NYC housing code violations [37, 42]. US cities and counties often have local housing codes that are designed to assure renters of minimal standards of housing; therefore, an option for addressing renters' issues is to refer patients to local low- or no-cost legal assistance organizations [43]. Additionally, some foundations provide grants that help cancer patients with housing-related costs, such as rent, which may be helpful for immigrants without status, who may not have ready access to other resources [44]. There are also government benefits and programs, including through the Department of Housing and Urban Development and the USDA in rural communities, that can help with housing-related costs and needs, if patients meet 
eligibility requirements, which include immigration status [38].

In addition to screening for and recognizing housing and food insecurity during patient visits and referring patients to supportive services and resources, clinicians should consider advocating for policies and working closely with government and community organizations to facilitate change. Previous research has proposed a conceptual model informed by the social ecologic model to address food insecurity [45]. Based on this, we recommend that at the societal level, policy can be influenced by producing research evidence; at the community level, increased awareness of and screening for food insecurity are needed, and at the individual level, staff should be designated as financial navigators and trained and utilized to perform this role [45]. Additionally, health plans could be incentivized to provide integrated medical and social services to low-income and minority patients who screen positive for housing and food insecurity. At Hennepin Health (Minnesota), which offers comprehensive housing and social services navigation and intensive case management to low-income Medicaid patients, quality of life improved among patients with various medical conditions, and emergency department visits decreased by $9.1 \%$ within 2 years of program implementation [46, 47].

In New York State, the Delivery System Reform Incentive Payment Program has focused on creating partnerships between hospitals and community-based service providers to reduce avoidable hospitalizations among Medicaid patients [48]. The program includes social determinants of health screening in public hospitals, including for housing and food insecurity, and recognizes the importance of addressing social determinants of health to achieve their overall goal [48]. Health care organizations that bring together medical and social services in one location can play an important role in increasing overall patient health and well-being. A longterm investment among hospital systems, health plans, and public and government organizations could enhance clinical and social services, address substandard housing, housing insecurity, homelessness, and food insecurity and reduce these threats to patient survival and well-being.

\section{Study limitations}

This study had some limitations. The study sample was a convenience sample of medically underserved cancer patients served in the 11 cancer clinics in NYC that participate in the ICCAN program. As such, our findings are not generalizable to the overall cancer patient population. Future studies are needed to assess cancer patient socioeconomic needs in other settings, including rural and suburban settings, as well as in clinics with different patient demographics. In addition, various patients entered the ICCAN program during different points in their treatment, and the study intake was administered at the time of patient entry into the program. Future studies should assess changes in housing and food insecurity at the beginning and throughout the continuum of care and outcomes following case management interventions. Another limitation was missing intake data due to patient time constraints/not feeling well. The missing data were excluded from data analysis, which could impact data analysis and results.

Acknowledgements The authors thank Sonya J. Smyk, MA, Memorial Sloan Kettering Cancer Center, for editorial support. She was not compensated beyond her regular salary.

Author contributions All authors listed have contributed sufficiently to the project to be included as authors, and all those who are qualified to be authors are listed in the author byline. All authors (F. Gany, I. Melnic, J. Ramirez, M. Wu, Y. Li, L. Paolantonio, N. Roberts-Eversley, V. Blinder, J. Leng) had a role in formulating the research question(s), designing the study, carrying it out, analyzing the data, and writing the article.

Funding This study and all authors were supported by National Cancer Institute: Core Cancer Center Support Grant (P30 CA008748), R01 CA230446 01, and the CCNY/MSKCC Partnership for Cancer Research Training \& Community Outreach (U54 CA137788), Laurie Tisch Illumination Fund, New York Community Trust, and AVON Foundation.

\section{Data availability N/A}

Code availability N/A

\section{Declarations}

Ethics statement This study was conducted according to the guidelines laid down in the Declaration of Helsinki and all procedures involving research study participants were approved by the Memorial Sloan Kettering Cancer Center's Institutional Review Board/Privacy Board and from each study site.

Consent to participate Written informed consent was obtained from all individual participants included in the study.

Conflict of interest To the best of our knowledge, no conflict of interest, financial or other, exists for any of the authors except for V. Blinder (Pfizer, Inc., consultant fee). This manuscript has not been previously published and is not under consideration in the same or substantially similar form in any other peer-reviewed media.

\section{References}

1. Gery P, Guy J, Ekwueme DU, Yabroff KR, Dowling EC, Li C, Rodriguez JL, Moor JSd, Virgo KS (2013) Economic burden of cancer survivorship among adults in the United States. J Clin Oncol 31:3749-3757

2. Phillips S, Raskin SE, Harrington CB, Brazinskaite R, Gany FM (2019) "You have to keep a roof over your head": a qualitative study of housing needs among patients with cancer in New York City. J Oncol Pract 15:e677-e689 
3. Stein L (1950) A study of respiratory tuberculosis in relation to housing conditions in Edinburgh: I.-The Pre-War Period. Br J Soc Med 4:143-169

4. Zolopa AR, Hahn JA, Gorter R, Miranda J, Wlodarczyk D, Peterson J, Pilote L, Moss AR (1994) HIV and tuberculosis infection in San Francisco's homeless adults. Prevalence and risk factors in a representative sample. JAMA 272:455-461

5. Vaughan JW, Platts-Mills TAE (2000) New approaches to environmental control. Clin Rev Allergy Immunol 18:325-339

6. Roberts JW, Dickey P (1995) Exposure of children to pollutants in house dust and indoor air. Rev Environ Contam Toxicol 143:59-78

7. Office of Disease Prevention and Health Promotion (2020) Housing instability. US Department of Health and Human Services. https://www.healthypeople.gov/2020/topics-objectives/ topic/social-determinants-health/interventions-resources/housi ng-instability. Accessed December 14, 2020

8. Economic Research Service (2020) Food security in the US. US Department of Agriculture. https://www.ers.usda.gov/topics/food-nutrition-assistance/food-security-in-the-us/. Accessed December 14, 2020

9. Furness BW, Simon PA, Wold CM, Asarian-Anderson J (2004) Prevalence and predictors of food insecurity among low-income households in Los Angeles County. Pub Health Nutr 7:791-794

10. Coleman-Jensen A, Matthew P. Rabbitt, Christian A. Gregory, Anita Singh (2019) Household food security in the United States in 2018. U.S. Department of Agriculture, Economic Research Service. https://www.ers.usda.gov/publications/pubdetails/?pubid=94848. Accessed December 14, 2020

11. Cutts DB, Meyers AF, Black MM, Casey PH, Chilton M, Cook JT, Geppert J, Ettinger de Cuba S, Heeren T, Coleman S, RoseJacobs R, Frank DA (2011) US housing insecurity and the health of very young children. Am J Pub Health 101:1508-1514

12. Lepore SJ, Evans GW, Schneider ML (1991) Dynamic role of social support in the link between chronic stress and psychological distress. J Pers Soc Psychol 61:899-909

13. Evans GW, Lepore SJ, Shejwal BR, Palsane MN (1998) Chronic residential crowding and children's well-being: an ecological perspective. Child Dev 69:1514-1523

14. Kushel MB, Gupta R, Gee L, Haas JS (2006) Housing instability and food insecurity as barriers to health care among low-income Americans. J Gen Intern Med 21:71-77

15. Gany F, Leng J, Ramirez J, Phillips S, Aragones A, Roberts N, Mujawar MI, Costas-Muniz R (2015) Health-related quality of life of food-insecure ethnic minority patients with cancer. $\mathrm{J}$ Oncol Pract 11:396-402

16. Sullivan AF, Clark S, Pallin DJ, Camargo CA Jr (2010) Food security, health, and medication expenditures of emergency department patients. J Emerg Med 38:524-528

17. Bengle R, Sinnett S, Johnson T, Johnson MA, Brown A, Lee JS (2010) Food insecurity is associated with cost-related medication non-adherence in community-dwelling, low-income older adults in Georgia. J Nutr Elder 29:170-191

18. Simmons LA, Modesitt SC, Brody AC, Leggin AB (2006) Food insecurity among cancer patients in kentucky: a pilot study. $\mathrm{J}$ Oncol Pract 2:274-279

19. Whitaker RC, Phillips SM, Orzol SM (2006) Food insecurity and the risks of depression and anxiety in mothers and behavior problems in their preschool-aged children. Pediatrics 118:e859

20. Seligman HK, Bindman AB, Vittinghoff E, Kanaya AM, Kushel MB (2007) Food insecurity is associated with diabetes mellitus: results from the National Health Examination and Nutrition Examination Survey (NHANES) 1999-2002. J Gen Intern Med 22:1018-1023
21. Stuff JE, Casey PH, Szeto KL, Gossett JM, Robbins JM, Simpson PM, Connell C, Bogle ML (2004) Household food insecurity is associated with adult health status. J Nutr 134:2330-2335

22. Young S, Wheeler AC, McCoy SI, Weiser SD (2014) A review of the role of food insecurity in adherence to care and treatment among adult and pediatric populations living with HIV and AIDS. AIDS Behav 18(Suppl 5):S505-S515

23. Braveman P, Gottlieb L (2014) The social determinants of health: it's time to consider the causes of the causes. Public Health Rep 129(Suppl 2):19-31

24. Laraia BA, Leak TM, Tester JM, Leung CW (2017) Biobehavioral factors that shape nutrition in low-income populations: a narrative review. Am J Prev Med 52:S118-S126

25. Gany F, Ramirez J, Nierodzick ML, McNish T, Lobach I, Leng J (2011) Cancer portal project: a multidisciplinary approach to cancer care among Hispanic patients. J Oncol Pract 7:31-38

26. U.S. Department of Housing and Urban Development (2007) Measuring overcrowding in housing http://www.huduser. org/publications/pdf/measuring_overcrowding_in_hsg.pdf. Accessed July 15, 2014

27. Economic Research Service (2012) U.S. Household Food Security Survey Module: three-stage design, with screeners. US Department of Agriculture. https://www.ers.usda.gov/media/ 8271/hh2012.pdf Accessed December 14, 2020, 2020

28. Peduzzi P, Concato J, Kemper E, Holford TR, Feinstein AR (1996) A simulation study of the number of events per variable in logistic regression analysis. J Clin Epidemiol 49:1373-1379

29. Cao J, Zhang S (2014) Multiple comparison procedures. JAMA 312:543-544

30. IBM Corp (2016) IBM SPSS Statistics for Windows, Version 24.0. IBM Corp, Armonk, NY

31. NYC Health + Hospitals (2016) Community health needs assessment. NYC Health + Hospitals. https://www.nychealtha ndhospitals.org/metropolitan/wp-content/uploads/sites/10/2016/ 08/chna-metropolitan.pdf. Accessed December 14, 2020

32. NYC Health (2018) New York City community health profiles. NYC.gov. https://www1.nyc.gov/site/doh/data/data-publicatio ns/profiles.page. Accessed 14 Dec 2020

33. Economic Research Service (2019) Key statistics \& graphics. US Department of Agriculture. https://www.ers.usda.gov/topics/food-nutrition-assistance/food-security-in-the-us/key-stati stics-graphics/\#householdtype. Accessed December 14, 2020

34. Louis-Jean J, Cenat K, Njoku CV, Angelo J, Sanon D (2020) Coronavirus (COVID-19) and racial disparities: a perspective analysis. J Racial Ethn Health Disparities 7:1039-1045

35. Bowen EA, Bowen SK, Barman-Adhikari A (2016) Prevalence and covariates of food insecurity among residents of singleroom occupancy housing in Chicago, IL, USA. Public Health Nutr 19:1122-1130

36. Sano Y, Garasky S, Greder KA, Cook CC, Browder DE (2011) Understanding food insecurity among Latino immigrant families in rural America. J Fam Econ Issues 32:111-123

37. NYU Furman Center (2018) State of New York City's housing and neighborhoods in 2018. NYU Furman Center. https:// furmancenter.org/files/sotc/2018_SOC_Full_2018-07-31.pdf. Accessed December 14, 2020

38. Affordable Housing Online (2020) Housing for eligible noncitizens. ApartmentSmart.com. https://affordablehousingonl ine.com/guide/housing-for-immigrants/eligible-noncitizens. Accessed December 14, 2020

39. Chokshi DA (2018) Income, poverty, and health inequality. JAMA 319:1312-1313

40. Office of Diseaese Prevention and Health Promotion (2019) Social determinants of health. US Department of Health and Human Services. https://www.healthypeople.gov/2020/ 
topics-objectives/topic/social-determinants-of-health. Accessed December 14, 2020

41. Freund KM, Battaglia TA, Calhoun E, Dudley DJ, Fiscella K, Paskett E, Raich PC, Roetzheim RG (2008) National cancer institute patient navigation research program: methods, protocol, and measures. Cancer 113:3391-3399

42. City of New York Title 27 - Chapter 2 Housing Maintenance Code NYC.gov. https://www1.nyc.gov/assets/buildings/pdf/Housi ngMaintenanceCode.pdf. Accessed December 14, 2020, 2020

43. Abt Associates and NYU Furman Center (2020) Local housing solutions. Abt Associates and NYU Furman Center. https://www. localhousingsolutions.org/. Accessed December 14, 2020

44. Cancer Financial Assistance Coalition. CancerCare. https://www. cancerfac.org/. Accessed December 14, 2020

45. Schroeder K, Smaldone A (2015) Food insecurity: a concept analysis. Nurs Forum 50:274-284

46. Blewett LA, Owen RA (2015) Accountable care for the poor and underserved: Minnesota's Hennepin Health model. Am J Public Health 105:622-624
47. Sandberg SF, Erikson C, Owen R, Vickery KD, Shimotsu ST, Linzer M, Garrett NA, Johnsrud KA, Soderlund DM, DeCubellis J (2014) Hennepin Health: a safety-net accountable care organization for the expanded Medicaid population. Health Aff (Millwood) 33:1975-1984

48. Gusmano MK, Thompson FJ (2015) An examination of Medicaid delivery system reform incentive payment initiatives under way in six states. Health Aff (Millwood) 34:1162-1169

Publisher's note Springer Nature remains neutral with regard to jurisdictional claims in published maps and institutional affiliations. 